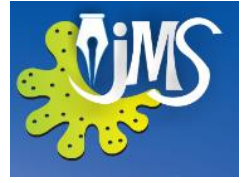

\title{
A Comparative Study of Demand for Medical Care on Non Communicable Diseases: Western vs. Alternative
}

\author{
${ }^{1}$ P D G L Samaraweera and ${ }^{1}$ M D J W Wijesinghe \\ ${ }^{1}$ Department of Economics and Statistics, Sabaragamuwa University of Sri Lanka
}

\begin{abstract}
Medical care is an input to the production of health. People get treatment for their health issues under western medicine, complementary and alternative medicine. Western medicine can be identified as the most famous and modern medical care system in the world. Complementary and alternative medicine refers to a variety of health practices as ayurveda, homeopathy, acupuncture, herbs, yoga, etc . Considering Sri Lankan context, with the rapid increase of ageing population, there is a growing trend in non communicable diseases. Most of people tend to use these two systems to recover from non communicable diseases as asthma, cholesterol, hypertension, arthritis, etc. The main objective of this study was to distinguish between the demand for alternative medicine and western medicine related to non communicable diseases. It was considered socio demographic and economic factors for demand in medical care for both sectors. Primary data was based on Arogya private hospital and Siddhayurvedini private ayurvedic care institution in Gampaha. It was selected 100 non communicable disease patients using systematic sampling method. Logistic regression model was mainly used to distinguish between the alternative and western medical care. According to the findings of this study, females are more likely to demand for both medical cares. Middle age, unemployed, arthritis patient and duration of disease 2-5 years cause to raise demand for alternative medical care. Diabetic patient, employed, believing health status as serious and having employer provided insurance cause to raise demand for western medical care. Relative to the demand for alternative medical care, living in rural area and lower educated people are negatively associated with demand for western medical care.
\end{abstract}

KEYWORDS: Demand, Western, alternative, non communicable diseases

Corresponding author: M. D. J.W.Wijesinghe, eMail: jayaniwijesinghe@yahoo.com 


\section{INTRODUCTION}

Medical care is an input to the production of health. It has been recognized the importance of health as a kind of human capital for producing income and performing other activities (Grossman, 2000). People get treatment for their health problems under western medicine as well as complementary and alternative medicine. Western medicine can be identified as the most famous and modern medical care system in the world. Complementary and alternative medicine refers to a variety of health practices as Siddha, Ayurveda, Unani, homeopathy, acupuncture, herbs, yoga etc.

According to Grossman (1972), health demand consists of two elements as consumption effect and investment effect. Considering the consumption, health makes people feel better and yields utility while investment increases the number of healthy days to work and to earn income. Further, it was generated three hypotheses on the impact of age, education and wage rate on the demand for health by Grossman. Increasing the elasticity of demand will cause to huge decrease in the optimal stock of health with age while the demand for medical care rises with the wage. Concerning the education the more educated people would demand more health but less medical care.

Wagstaff (1986) has developed an idea regarding individual demand for health based on indifference map, health production function and budget constraint. An individual likes to attain highest indifference curve because it offer more consumption for a given level of health. According to Wagstaff, relationship between health inputs and health output is represented by health production function, which is positive. Budget constraint indicates that individuals have only limited income to finance their health production and consumption activities. The slope of the budget constraint is revealed that it must be given up the number of units of consumption to obtain one more unit of health input.

In Sri Lanka context, with the rapid increase of ageing population, there is a growing trend in non-communicable diseases. Most people tend to use these two systems for non-communicable diseases such as asthma, cholesterol, hypertension, arthritis etc. Demand in medical care for non-communicable diseases can be varied according to socio-cultural factors, demographic factors, health factors and economic factors. Therefore, to tackle the problem of non-communicable diseases it is important to identify the demand in medical care for western medicine and alternative medicine. Currently, there is a need of research for the development of alternative medicine in Sri Lanka and it will be helped for policy makers in health sector.

\subsection{Objectives}

The main objective is to identify the comparative demand for medical care between western and alternative medicine related to non communicable diseases. The demand for medical care can be varied with economic, demographic, health and time factors. Therefore the study carried out to find out the major factors that affect on demand for medical care between western and alternative medicine.

\subsection{Problem statement}

Among Sri Lankan people, there is a demand for alternative and western medicine for non communicable diseases like diabetes, asthma, arthritis, back pains. Patients tend to get treatment under western medicine as well as alternative medicine. Sri Lankan alternative medicine is provided as Ayurvedic, Homeopathy and Acupuncture. Ayurvedic medicine is the major alternative service among other medical care. There are currently 62 Ayurvedic hospitals and 208 central dispensaries in the public system and they 
served almost three million people. It is about 11 percent of Sri Lanka total population in 2010 (http://en.wikipedia.org/wiki/Ayurveda).

In 2001, non communicable diseases accounted for 71 percent of all deaths in Sri Lanka. It has shown that the chronic non communicable diseases mortality is 20-30 percent higher in Sri Lanka according to an analysis of age-standardized data for 1991-2001 (Central Bank of Sri Lanka, 2009). Share of patients discharges accounted by non communicable diseases at health care institutions in Sri Lanka in 2005 can be identified as asthma $4.2 \%$, diabetes $1.2 \%$ and cancer $2.3 \%$ (Non communicable disease statistics-2007 hospital discharge data). Percentage distribution of population who suffered from chronic illness in 2009 can be mentioned as heart disease $7.5 \%$, blood pressure $21.3 \%$, diabetes $15.75 \%$, asthma $10.1 \%$ and arthritis 5.9\% (Household Income and Expenditure Survey- 2009/2010).

To tackle the problem of non communicable diseases it is important to identify the demand in medical care for western medicine and alternative medicine. Both western and alternative medicine specially, Ayurvedic medicine has an important role for tackling the problem of non communicable diseases. Due to the dissatisfaction of western medicine, people tend to get treatment under alternative medicine. Some people believe in more on western medicine than alternative medicine. It can be varied according to their demographic, social and economic factors of patients. In here it is expected to find out the socio demographic, economic, time and health factors that affect to the demand are in medical care for western medicine and alternative medicine related to non communicable diseases in Sri Lanka.

\subsection{Importance of the research}

Gradually, demand in medical care is increased due to rapid increase of population In Sri Lanka. The quality of public western and alternative medicine in Sri Lanka is not in a satisfactory level being as a free service provider due to insufficient infrastructures in that scenario, the quality of health care is in low level. Therefore, patients tend to get treatments under private medical care providers. However considering the health field, it is hard to find research related to private medical care specially related to non communicable diseases. Therefore, this study will help to fulfill the research gap in health field and policy makers who deal in this field.

\subsection{Literature review}

Considering the empirical studies, Acton (1975) found that high income earned people are more likely to use the private sector medical care. Further he concluded that being a man, having health insurance by a family member and distance for the service provider was significant factors related to demand in western medical care. Opposed to this finding Feng (2007) revealed that effect of medical insurance was not significant for demand in western medical care. Some studies found strong associations between demand for western medical care and education (Fabbri \& Monfurdini, 2002; Sarah, 2004). Considering the gender and demand for medical care some researchers revealed that females are more likely to demand for medical care (Miller, 1990; Blais et al., 1997; Votova, 2003; Arcury et al., 2006). Regarding the religion, Bello (2005) found that there was an inverse relationship with alternative medical care and religion. Age was identified as a significant factor in demand for alternative medical care by Zhang, 2006 and Grants, 2007. Peter (1982) and Sandra (2002) concluded that residence sector is affected for demand in western medical care. 
Further, Guethlin et al. (2009) have found the significant association between alternative medical care and employment status. Upchurch \& Chyu (2004), Metcalfe (2010) and Herman et al. (2004) showed that there was a strong relationship between illness factors and demand for medical care. According to Zhang (2006) ,Guethlin et al. (2009), Kanodia et al. (2010) and Chang et al. (2011) side effects and health beliefs affect to demand for medical care.

\section{METHODOLOGY}

Primary data were gathered using questionnaires through a hospital survey. It was collected data on education, income, nature of illness, transport mode to visit medical care, marital status, region of the residence and medical care expenditure (indirect and direct cost) related to demand in medical care. It was selected 100 non communicable disease outpatients from a hospital clinic in Arogya private hospital and Siddhayurvedini ayurvedic care institution in Gampaha which are the main private hospital in this district .In here it was used systematic random sampling method due to dealing with an unknown population framework.

The data analyze was carried out in two major forms.

- Analyze the descriptive statistics using graphs, tables, bar charts and pie charts.

- Estimate the model using the Binary logistic regression model to identify the factors that affect on western and alternative medical care. Binary logistic regression can be explained as follows.

$\operatorname{logit}(p)=b_{0}+b_{1} x_{1}+b_{2} x_{2}+b_{3} x_{3}+\ldots+b_{k} x_{k}$

$\mathrm{Y}$ is the dependent variable representing demand for medical care western and alternative medical care. (demanding western medical care $=1$ and demanding alternative medical care $=0$ ) and independent variables considered by the study are sex ,age, residential sector, marital status, ethnicity ,income, Employment status, nature of health issue Time factors, price of medical care, having health insurance as continues variables.

\section{RESULTS AND DISCUSSION}

The following section explain the findings of the study using descriptive analyze and binary logistic regression.

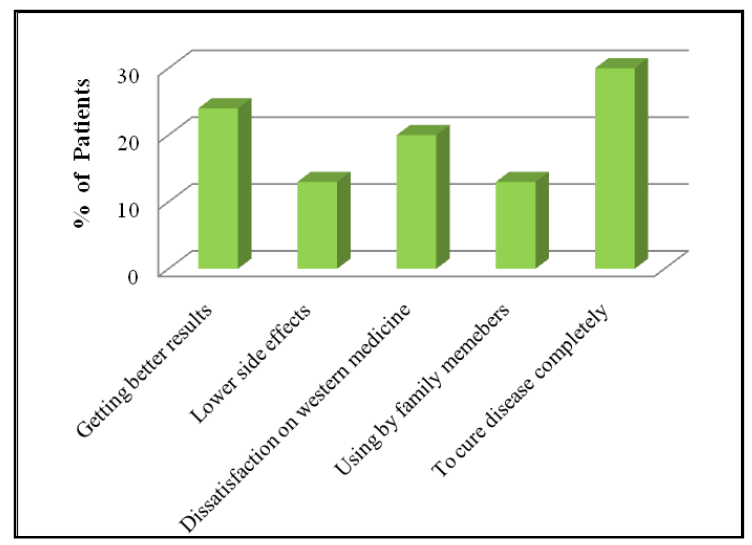

Figure 1. Reasons for using Alternative medical care

Source: Sample survey, 2013

Considering the patients in alternative medical care they use alternative medical care due to above reasons. Majority of them use alternative medical care due to cure disease completely. Since the ancient time Sri Lankan people are very close to alternative medicine and most of time they tended to go for traditional healers for their health problems. It is highly depend on their culture and traditional beliefs. Majority of patients use alternative medical care due to dissatisfaction on western medicine. Similar result was found by Kanodia, et al. 2010; Chang, et al. 2011 and Teper \& Tsai, 2008. 


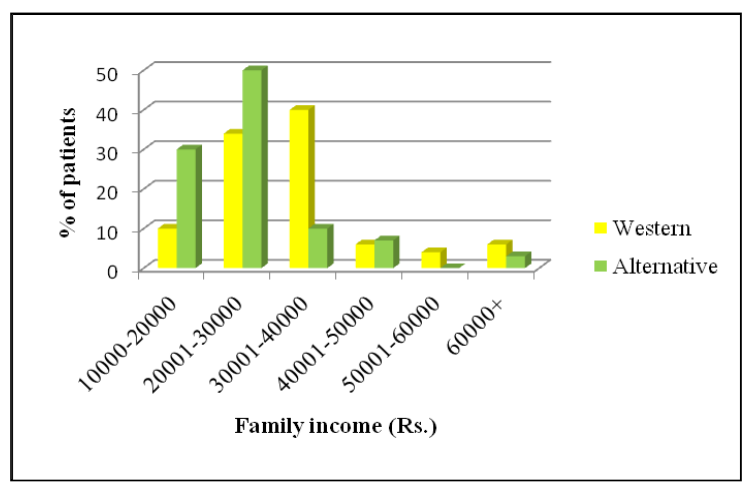

Figure 2. Demand for medical care by family income of patients

Source: Sample survey, 2013

Considering the above figure, family income of patients is varied between 10,000 and 60,000 or more per month. Most of patients who use alternative medical care are in the 20001-30000 income groups. On the other hand, it is reported large portion of patients who use western medical care under the 3000140000 income groups. It means being a high income earner causes to demand for private medical care. There is a chance to have good health for them due to the high income. Concerning the results of empirical studies, some researchers identified income as a significant variable related to private medical care as in this study (Acton, 1975; Sarah, et al. 2004; Garrow \& Egede, 2006; McMahan \& Lutz, 2004; Votova, 2003).

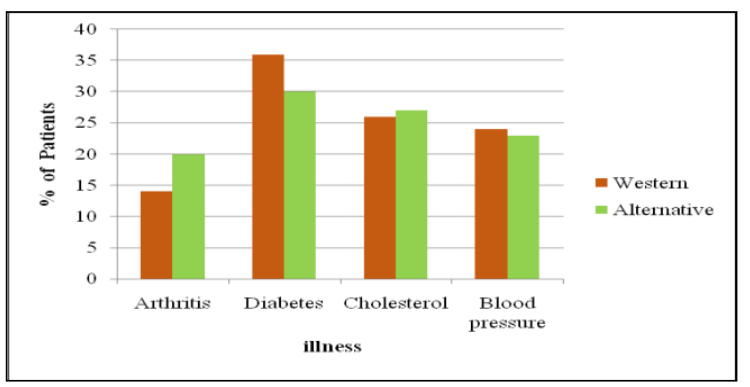

Figure 3. Demand for medical care and types of illness of patients

Source: Sample survey, 2013
According to the above chart it is clear that being a diabetic patient causes to demand more for western medical care. There is a high demand for western medical care by diabetic, cholesterol and blood pressure patients. One fifth of patients who suffer from arthritis tend to get alternative medical care than western medical care. The reason is they believe that it can be completely cured arthritis through alternative medicine. Association between the nature of illness and demand for alternative care was found by Metcalfe, et al. 2010; Bhargava, 2007; Grant, et al. 2007. In addition to them, Zhang, 2006 found that blood pressure, virus infection, arthritis and heart problems were reported as most common health problems under complementary and alternative medical care. Caballero et al. 2010 has revealed that people with diabetes were 2.5 times as likely to use complementary therapies compared to people without diabetes.

\subsection{Model fitting}

In here it is considered about the factors which affect to the demand for medical care between western medicine and alternative medicine.

\subsubsection{Step 1 - Null model}

Stepwise procedure is used to identify the suitable model to explain the data. The first step is focused on to analyzing the result of null model. $\mathrm{P}$ value of the intercept term is considerable at $5 \%$ level significant. When the null model is significant, value of the $\boldsymbol{\beta}_{\mathbf{0}}$ is 0.847 .

$$
\operatorname{logit}(\pi)=\beta_{0}
$$

Table 1. Null model

\begin{tabular}{|l|l|l|l|l|l|}
\hline & B & Wald & D & Sig & $\operatorname{Exp(B)}$ \\
\hline $\begin{array}{l}\text { Consta } \\
\text { nt }\end{array}$ & 0.847 & 15.076 & 1 & 0.000 & 2.333 \\
\hline
\end{tabular}

Source: Sample survey, 2013 


\subsubsection{Step 2-Model with one variable}

\subsection{A. Model with residence and demand for medical care}

$$
\begin{gathered}
\operatorname{logit}\left(\pi_{i}\right)=\beta_{0}+\beta_{i}^{\text {rural }}+\beta_{i}^{\text {semi urbun }} \\
+\beta_{i}^{\text {urbun }}
\end{gathered}
$$

Table 2. Model with residence and demand for

\begin{tabular}{|c|c|c|c|c|c|c|}
\hline $\begin{array}{c}\text { Paramete } \\
\mathbf{r}\end{array}$ & B & Wald & DF & $\begin{array}{c}\mathbf{P} \\
\text { value }\end{array}$ & $\begin{array}{c}\operatorname{Exp} \\
\text { (B) }\end{array}$ & $\begin{array}{c}\text { Referen } \\
\text { ce } \\
\text { category }\end{array}$ \\
\hline Residence & & 15.285 & 2 & 0.000 & & Urban \\
\hline Rural & 2.015 & 11.669 & 1 & 0.001 & 0.133 & \\
\hline $\begin{array}{l}\text { Semi } \\
\text { urban }\end{array}$ & 0.069 & 0.014 & 1 & 0.905 & 1.071 & \\
\hline Constant & 1.386 & 12.300 & 1 & 0.000 & 4.000 & \\
\hline
\end{tabular}
medical care

Source: Sample survey, 2013

According to above table, equalizing first reference category of the residence care variable to the zero results that total parameter value is less than 0.05 . It means residence and demand for medical care is significant (residence is significant for the one variable with model).In here, considering separately the rural and semi urban reference categories, $p$ value of the rural reference category is less than 0.05 means it is significant. It can be said that living in semi urban area is not significant with medical care. With reference to the patients living in urban area demand for western medical care decreases by 0.133 times for the patient living in rural area. It is represented that demand for western medical care decreases by $35 \%$ for the patients living in rural area than to patients in urban area.

\subsection{B. Model with education and demand for medical care}

$$
\begin{aligned}
\operatorname{logit}\left(\pi_{i}\right)=\beta_{0}+ & \beta_{i}^{\text {no schooling }}+\beta_{i}^{5 \text { years }} \\
& +\beta_{i}^{8 \text { years }}+\beta_{i}^{10 \text { years }}+\beta_{i}^{11 \text { years }} \\
& +\beta_{i}^{13 \text { years }}+\beta_{i}^{\text {degree }}
\end{aligned}
$$

\begin{tabular}{|c|c|c|c|c|c|c|}
\hline Parameter & B & Wald & DF & $\begin{array}{c}P \\
\text { value }\end{array}$ & $\begin{array}{c}\text { Exp } \\
\text { (B) }\end{array}$ & $\begin{array}{c}\text { Referen } \\
\text { ce } \\
\text { categor }\end{array}$ \\
\hline $\begin{array}{l}\text { Years of } \\
\text { education }\end{array}$ & & $\begin{array}{r}15.30 \\
8\end{array}$ & 6 & .018 & & \multirow[t]{8}{*}{ Degree } \\
\hline $\begin{array}{l}\text { No } \\
\text { schooling }\end{array}$ & -3.664 & 5.569 & 1 & .018 & .026 & \\
\hline 5 years & -1.179 & .597 & 1 & .440 & .308 & \\
\hline 8 years & -3.171 & 7.535 & 1 & .006 & .042 & \\
\hline 10 years & -1.872 & 1.360 & 1 & .244 & .154 & \\
\hline 11 years & -1.402 & 1.467 & 1 & .226 & .246 & \\
\hline 13 years & -1.312 & 1.391 & 1 & .238 & .269 & \\
\hline constant & 2.565 & 6.109 & 1 & .013 & 13.00 & \\
\hline
\end{tabular}

Table 3. Model with education and demand for medical care

Source: Sample survey, 2013

According to above table, $\mathrm{P}$ value of the total parameter is less than 0.05 indicating there is an association between education and demand for medical care. Considering separately other reference categories, only 5 years and 8 years education categories are significant with medical care while other categories are not significant with medical care. Demand for medical care decreases for patients who are no schooling by 0.026 times relative to the patients who have degrees. It means demand for western medical care decreases by $25 \%$ from the no schooling patients. Concerning the eight years education category, demand for western medical care decreases by $35 \%$. . Similar to this finding, Sarah et al. (2004) found that there is a significant association between education level and demand for private western medical care. Opposed to this, Sandra (2002) found that people having 4 to 7 years of education are more likely to seek health care than anyone else. Further, Grossman (1972) generated hypothesis on the impact of education on the demand for 
health as more educated people would demand more health but less medical care.

\subsection{C. Model with having disease by family member and demand for medical care}

$$
\operatorname{logit}\left(\pi_{i}\right)=\beta_{0}+\beta_{i}^{y e s}+\beta_{i}^{\text {no }}
$$

Table 4. Model with having disease by family member and demand for medical care

\begin{tabular}{|l|l|l|r|r|r|c|}
\hline $\begin{array}{l}\text { Paramete } \\
\text { r }\end{array}$ & \multicolumn{1}{|c|}{ B } & Wald & \multicolumn{1}{c|}{ DF } & \multicolumn{1}{c|}{$\begin{array}{c}\text { P } \\
\text { value }\end{array}$} & $\begin{array}{c}\text { Exp } \\
\text { (B) }\end{array}$ & $\begin{array}{c}\text { Reference } \\
\text { category }\end{array}$ \\
\hline Yes & .981 & 4.618 & 1 & .032 & 2.667 & No \\
\cline { 1 - 3 } Constant & .405 & 1.973 & 1 & .160 & 1.500 & \\
\hline
\end{tabular}

Source: Sample survey, 2013

By equalizing the last reference category of having disease by family member variable to the zero, it can be identified that the $\mathrm{p}$ value is less than 0.05.It denotes that having disease by family member and demand for western medical care is significant. With reference to the without having disease by family member, demand for western medical care increase by 2.667 times for having disease by family member. It reveals having non communicable disease by family member causes to increase the demand for western medical care by $80 \%$.If a member of a family suffer from a disease, members of the family pay more attention on their health than previous. Then they tend to demand more for western medical care.

\subsection{D. Model with medical insurance and demand for medical care}

$$
\operatorname{logit}\left(\pi_{i}\right)=\beta_{0}+\beta_{i}^{y e s}+\beta_{i}^{n o}
$$

Table 5. Model with medical insurance and demand for medical care

\begin{tabular}{|l|r|r|r|r|r|c|}
\hline $\begin{array}{l}\text { Paramete } \\
\mathrm{r}\end{array}$ & \multicolumn{1}{|c|}{ B } & Wald & \multicolumn{1}{|c|}{ DF } & P value & Exp(B) & $\begin{array}{c}\text { Reference } \\
\text { category }\end{array}$ \\
\hline Yes & 1.380 & 6.392 & 1 & .011 & 3.974 & No \\
\hline Constant & .445 & 3.013 & 1 & .083 & 1.560 & \\
\hline
\end{tabular}

Source: Sample survey, 2013
When it is equalized the last reference category of medical insurance variable to the zero, $p$ value is less than 0.05 .It reveals that there is an association between medical care insurance and demand for western medical care. Demand in western medical care increases by 3.974 times for the patients having medical insurance relative to the patients without having medical insurance. It means demand for western medical care increases by $86 \%$ for the patients having medical insurance. Having a medical insurance causes to increase demand for western medical care as well as decreasing the cost for western medical care in the long run. It was found similar results by Acton (1975) and Sandra (2002).Patients can cover their cost of medical care through medical insurance hence they are more likely to demand for medical care. Opposed to this, Feng et al. (2007) have revealed that effect of medical insurance wasn't significant.

\subsection{E. Model with direct cost and demand for medical care}

$$
\begin{aligned}
& \operatorname{logit}\left(\pi_{i}\right)=\beta_{0}+\beta_{i}^{1500 \text { or less }}+ \\
& \beta_{i}^{1501-2500}+\beta_{i}^{2501-3500}+\beta_{i}^{3501-4500}+ \\
& \beta_{i}^{4501-5500}+\beta_{i}^{5500+}
\end{aligned}
$$

Table 6. Model with direct cost and demand for medical care

\begin{tabular}{|l|l|l|l|l|l|l|}
\hline & & & & & & $\begin{array}{c}\text { Ref } \\
\text { eren } \\
\text { ce } \\
\text { Parameter }\end{array}$ \\
\cline { 1 - 5 } Direct cost \\
cate \\
gory \\
less
\end{tabular}

Source: Sample survey, 2013 
According to above table, total parameter value for the direct cost variable is less than 0.05 indicating there is an association between demand for western medical care and direct cost. Considering separately reference categories, no variable associates with demand for western medical care. For private medical care channeling, people have to bear high cost. They have to bear cost for drugs, doctor fees and testing fees. If the direct cost is high, it will be decreased the demand for western medical care. This finding is supported by Wirick (1966).

\subsection{Step 3- Model with demand for medical care}

Although there is a logistic regression model with one variable, the objective of data analysis is to obtain a best fitted logistic regression model. Therefore, in this third step, it is considered the variables affected to determine the one variable with logistic regression model for developing the best fitted logistic regression model.

Table 8. Model with demand for medical care

\begin{tabular}{|l|l|l|l|l|}
\hline Variable & B & P value & Exp (B) & $\begin{array}{l}\text { Reference } \\
\text { category }\end{array}$ \\
\hline Total parameter & & 0.01 & & \multirow{2}{*}{ Urban } \\
\cline { 1 - 3 } Rural & -2.215 & 0.002 & 0.109 & \\
\hline Semi urban & 0.138 & 0.831 & 1.148 & \\
\hline Total parameter & & 0.031 & & \multirow{2}{*}{ Degree } \\
\hline No schooling & -3.560 & 0.035 & 0.028 & \\
\hline 5 years & -1.222 & 0.466 & 0.295 & \\
\hline 8 years & -3.400 & 0.006 & 0.033 & \\
\hline 10 years & -0.821 & 0.636 & 0.440 & \\
\hline 11 years & -1.205 & 0.333 & 0.300 & \\
\cline { 1 - 3 } 13 years & -1.581 & 0.187 & 0.206 & \\
\hline Constant & 3.205 & 0.005 & 24.647 & \\
\hline
\end{tabular}

Source: Sample survey, 2013

It can be formed the best fitted logistic regression model as follows.

$$
\begin{aligned}
& \operatorname{logit}\left(\boldsymbol{\pi}_{\boldsymbol{x}}\right)=\boldsymbol{\beta}_{\mathbf{0}}+\boldsymbol{\beta}_{\mathbf{1}}^{\boldsymbol{A}}+\boldsymbol{\beta}_{2}^{\boldsymbol{B}} \\
& \operatorname{logit}\left(\pi_{x}\right)=3.205-2.215 \quad \text { rural }- \\
& 3.56^{\text {no schooling }}-3.4^{\text {8years }}
\end{aligned}
$$

$\mathrm{A}=$ Region of residence, $\quad \mathrm{B}=$ Education

$\beta_{0}, \beta_{1}, \beta_{2}=$ Parameters
According to the above best fitted logistic regression model, region of the residence and education are significant regarding the demand for western medical care. Considering the region of the residence which affects for the demand in western medical care, by equalizing the urban reference category to the zero, it decreases the demand in medical care for patient living in rural area by 0.109 times $(72.8 \%)$ relative to the patient living in urban sector. This finding is consistent with the findings of Peter (1982); Sandra (2002). Compared to the rural people, urban people have easy accessibility for medical care. Thus they can reduce their opportunity cost of time. Therefore, living in urban area increases the chance of looking for health care over living in rural areas. Most of rural people believe on alternative medical care due their culture as well as traditional believes. It can be concluded that region of residence is affected for demand in western medical care.

\section{CONCLUSION AND POLICY IMPLICATION}

Health is the one of key factor for development of the individual, household and country. Therefore people trend to demand western and alternative medicine to protect from various health issues. According to this study it was identified that high proportion of females are likely to demand for both alternative medical care and western medical care. Patients in 73-82 age categories are more likely to demand in western medical care while middle aged patients are more likely to seek alternative medical care. Considering the religion of patients majority of the patients in alternative medical care demanding are Buddhists. Further it can be seen that being a high income earner causes to demand for both western and alternative care. Regarding employment status, compared to unemployed patients, employed patients are more likely to demand for western medical care. Government employees are more 
likely to seek alternative medical care while private sector employees are more likely to seek western medical care. Receiving a medical allowance from the employer causes to increase the demand for western medical care. Therefore, majority of patients seeking western medical care are financially supported by themselves while more than half of alternative care patients gain financial support from the family members. Thus it is needed to introduce insurance scheme for alternative medical care. In Sri Lanka it is not covered cost of alternative medical care under the insurance system.

Comparing with world situation, most of countries have introduced health schemes for alternative medicine. Health insurance for western health care lowers the price of western care and thus increases the relative price of alternative health care, resulting in reduced demand for alternative health care. Thus people having insurance coverage for western medical care are reluctant to go for alternative care. It was found that even under the employerprovided private health plans, it is not covered cost for alternative care. It is better to introduce health insurance scheme regarding alternative care. Especially most of non communicable disease patients want to cure their diseases completely. Therefore, it is better to design insurance schemes for them by the health insurers. It will be very helpful to increase the demand for alternative care and decrease the cost of health care in the long run. Further, encouraging the patients through insurance schemes may have positive effects on individual health. Finally, it will cause to raise indirect demand for insurance sector.

Majority of patients use alternative medical care due to dissatisfaction on western medicine. Coming to get treatment for alternative care is highly influenced by relatives and friends. Due to the belief of fewer side effects, patients are more likely to use alternative medical care. Indirect expenditure is relatively high for patients obtaining alternative medical care. Total medical care cost of patients demanding western medical care is higher than alternative medical care. More than half of patients in both providers demand for medical care due to good personal autonomy and good quality regarding the service provider. Majority of the patients in alternative medical care are satisfied about the treatments. Considering education level and demand in medical care, It was identified a negative relationship between education and demand for western medical care. Considering Sri Lankan context, there is no incentive to persuade patients for alternative medical care. Most of people tend to go for western medical care. Reasons for moving to western medicine are they believe that western medicine have an ability to cure diseases quickly and easy accessibility. Further, there is a proper channeling service in the private western care. Comparing with the channeling service of western medicine, it cannot be seen proper channeling service for alternative care.

Currently, it is provided low quality drugs under the western medical care and there is no regulation regarding it. Due to this reason patients have to face various problems regarding their health conditions. This situation is similar for the alternative care providers. Both sectors have unqualified practitioners. Therefore it will be negatively affected for the future existence of the medical system in the country. To overcome these problems, it is needed to introduce regulations immediately. It can be suggested regulations as supervision of medical practitioners and introducing a national policy for medical drugs.

\section{REFERENCES}

ACTON JP. Non Monetary Factors in the Demand for Medical Services: Some Empirical Evidence. Journal of Political Economy. 1975; 83(3).

ARCURY TA, BEL RA, SNIVELY BM, SMITH SL, SKELLY AH, WETMORE LK, \& 
QUANDT SA. Complementary And Alternative Medicine Use As Health SelfManagement : Rural Older Adults With Diabetes. 2006; Available from :http://www.ncbi.nlm.nih.gov/pmc/articles/PM C1622916/ (Accessed on 20/11/2012).

BELLO RA. Determinants of Demand for Traditional Method of Healthcare Services in Osun State: Nigeria. 2005; Available from: http://www.unilorin.edu.Ng/publications/bellora /Determinants\%20of\%20Demand\%20for \% 20 Traditional \%20 Method \% 20of \%20Health \%20Care.pdf (Accessed on11/12/2012).

BHARGAVA V. Demand for Complementary and Alternative Medicine: An Economic Analysis.2007; Available from: http://www.rav e.ohiolink.edu/etdc/view?acc_num=osu1181736 111 (Accessed on 23/04/2012).

BLAIS R, MARGA A, \& ABOUBACAR A. How Different Are Users And Non-Users Of Alternative Medicine?. Canadian Journal of Public Health. 1997;88(3):159-162.

\section{CABALLERO LV, MORELLO CM,} CHYNOWETH ME, ROSINOL AP, POLONSKY WH, PALINKAS LA, \& EDELMAN SV. Ethnic Differences in Complementary and Alternative Medicine Use among Patients with Diabetes. 2007; Available from:http://www.ncbi.nlm.nih.gov/pmc/articles/ PMC3003303/ (Accessed on 04 /12/ 2012).

CENTRAL BANK. Annual Bank Report Sri Lanka, Colombo: Central Bank of Sri Lanka. 2009; 70-71

CHANG HA, TRIALONGO E, \& WALLS M. Use of Complementary and Alternative
Medicine among People with Type Two Diabetes in Taiwan: a Cross-Sectional Survey, 2010; Available from: http://www.hindawi. com/journals/ecam/2011/983792/ (Accessed on $25 / 04 / 2012$ )

EISENBERG DM, DAVIS RB, ETTNER S L, APPEL S, WILKEY S, ROMPAY MV, \& KESSELER RC. Trends in Alternative Medicine Use in the United States-97. 1998; Available from: http://www.jama.jamanetwork. com/article.aspx?articleid = $188148 \quad$ (Accessed on17 /12/ 2012).

FABBRI D \& MONFARDINI C. Public vs. Private Healthcare Demand in Italy.2002; Available from: http://www2.dse.unibo. it/wp/457.pdf (Accessed on 04 /12/ 2012).

FENG J, QIN B, \& YU Y. Wealth, Education and Demand for Medical Care.2007; Available from: http://www.profluming.com/Article/

UploadFiles/200703 /20070310224414483.pdf (Accessed on $10 / 05 / 2012$ )

GARROW D, \& EGEDELE. Association between Complementary and Alternative Medicine Use, Preventive Care Practices and Use of Conventional Medical Services among Adults with Diabetes. 2006:Available from: http://www.care.diabetesjournals.org/ content/ 29/1/15.full.pdf(Accessed on $20 / 12 / 2012$ )

GRANT JS, HILL W, WEINERT C, NICHOLS E, \& IDE B. Complementary Therapy and Older Rural Women: Who Uses It and Who Does Not?.2007;Available from: www. researchgate.net/...Complementary_therapy_and older_rural_women.../d912f50b635bdead98.pdf (Accessed on $02 / 12 / 2012$ )

GROSSMAN. United States of America: On The Concept Of Health Capital And The 
Demand For Health. The Journal of Political Economy. 1972; 80(2) Available from: http://www.ppge.urfgs.br/giacomo/arquivos/eco 02072/grossman-1972.pdf. (Accessed on 06 /12/2012)

GUETHLIN C, WALACH H, NAUMANN J, BARTSCH HH, \& ROSTOCK M. Characteristics of Cancer Patients Using Homeopathy Compared with Those in Conventional Care: A Cross Sectional Study.2009; Available from :http://www. an noncoxfordjournals.org/content/21/5/1094.full (Accessed on $25 / 04 / 2012$ )

HERMAN CJ, ALLEN P, PRASAD A, HUNT WC, \& BARDY TJ. Use of Complementary Therapies among Primary Clinic Patients with Arthritis.2004; Available from: http://www.nc bi.nlm.nih.gov/pmc/articles/PMC1277952/

(Accessed on19/12/2012)

HOUSEHOLD INCOME

AND

EXPENDITURE SURVEY Department of Census and Statistics, Ministry of Finance and Planning, Sri Lanka.2009/10; Available from: http://www.statistics.gov.lk/hies/hies2009 10finalreport.pdf (Accessed on 30 /05/2012)

http://en.wikipedia.org/wiki/Health (Accessed on 10 May 2012)

KANODIA AK, LEGEDZA ATR, DAVIS RB, EISENBERG DM, \& PHILLIPS RS. Perceived Benefit of Complementary and Alternative Medicine (CAM) for Back Pain: A National Survey.2010; Available from: http://www. jabfm.org/content /23/3/354.full (Accessed on $19 / 12 / 2012$ )
MCMAHAN S, \& LUTZ R. United States of America: Alternative Therapy Use among the Young - Old (Ages 65 to 74): An Evaluation of the MIDUS Database. Journal of Applied Gerontology. 2004; 23(2) Available from: http://www.aging.wisc. edu/midus/ findings/ pdfs/214. pdf (Accessed on 25/05/ 2012)

METCALFE A, WILLIAMS J, MACHESNEY J, PATTERN, SB, \& JETTE N. Use Of Complementary. And Alternative Medicine By Those With A Chronic Disease And The General Population - Results Of A National Population Based Survey.2010; Available from: http://www.biomedcentral.com/1472-6882/10/5 8(Accessed on 20 /12/ 2012)

MILLER JK. Use Of Traditional Korean Health Care By Korean Immigrants To The United States, Sociology and social research.2000; $75(1)$

\section{NON COMMUNICABLE DISEASE}

STATISTICS-2007. Hospital Discharge Data, Non Communicable Disease Unit, Ministry of health, Sri Lanka, September. 2011; Available from: http://203.94.76.60/NCD/temp/ ALLV1. dff (Accessed on 10/06/ 2012)

PETER SH. A model of the demand for medical and health services in Peninsular Maalaysia.1982:Available from: http://www .petersheller. com/documents/publications/ 14.pdf (Accessed on $6 / 05 / 2013$ )

SANDRA V. Demand for health care in Brazil: A preliminary analysis by regions. 2002; Available from: www.uc.pt/en/fmuc/phdhs/ Courses/.../analisar1_texto_1_.pdf (Accessed on $02 / 05 / 2013$ ) 
SARAH S, JULIET NO, IBRAHIM K, \& LAWSON D. Demand for Healthcare Services in Uganda Implications for Poverty Reduction.2004;Available from: http://www .mpra.ub.unimuenchen.de/8558/1/MPRApaper-8558.pdf (Accessed on $06 / 12 / 2012$ )

TEPER AM, \& TSAI E. Complementary And Alternative Medicine Use By Canadian University Students.2008; Available from: http://www.jptcp.com /cjep 06029_tsai_e5-e14r101687 (Accessed on $04 / 12 / 2012$ )

UPCHURCH DM, \& CHYU L. Use of Complementary and Alternative Medicine among American Women.2004; Available from :http://www.hawaii.edu/hivandaids/Use_of Complementary_and_AlternativeMedicine _Among_American_Women.pdf (Accessed on $04 / 12 / 2012$ )

VOTOVA KME. Complementary And Alternative Medicine Use Among Older Adults: 2003; Available from: http://www.sfu.ca/ uploads /page/02 / thesis_votova. pdf (Accessed on $15 / 11 / 2012$ )

WAGSTAFF A. (1986). The demand for health: theory and applications. Journal of Epidemiology and Community Health.1986;40 Available from: http://www.lingli.ccer. edu.cn/ ahe2012/week4/ Wagstaff.pdf (Accessed on $06 / 12 / 2012$ )
WIRICK GC. A Multiple Equation Model of Demand for Healthcare.1966; Available from: http://www.ncbi.nlm.nih.gov / pmc /articles / PMC1067346 / pdf / hsresearch 00591-0091.pdf (Accessed on $06 / 12 / 2012$ )

ZHANG AL. Complementary and Alternative Medicine Use in Australia: A National Populati -on based Study.2006; Available from: http://www.researchbank. rmit.edu.au/eserv/ rmit:10000/Zhang.pdf(Accessed on17/12/2012) 